\title{
A COMPLEXA EFETIVAÇÃO DO DIREITO À ATENÇÃO BÁSICA EM SAÚDE NO BRASIL: PARADOXOS TEÓRICOS E NORMATIVOS'
}

\author{
THE COMPLEX EFFECTIVATION OF THE RIGHT TO \\ BASIC HEALTH CARE IN BRAZIL: THEORETICAL AND \\ NORMATIVE PARADOXES
}

\section{Giovana Knorst Chaves ${ }^{2}$ Lais Dockorn Nunes Pereira ${ }^{3}$ Janaína Machado Sturza ${ }^{4}$}

DOI: https://doi.org/10.37767/2591-3476(2020)03

\section{RESUMEN:}

El derecho a la salud en Brasil, como señala nuestra Constitución federal de 1988, es un derecho de todos y un deber del Estado, garantizado a través de políticas sociales y económicas destinadas a reducir el riesgo de enfermedades y otras enfermedades y proporcionar acceso universal e igualitario a acciones y servicios para su promoción, protección y recuperación. Esta investigación tiene como objetivo analizar la realización del derecho a la salud a través del acceso al derecho a la atención básica de salud, especialmente políticas públicas articuladas y promovidas por el Ministerio de Salud. A cabo bajo la perspectiva reflexiva de las teorías de la Ley Fraterna y la Ley de Vida, para demostrar que el derecho a la salud es un bien común para todos, en este escenario, la necesaria realización de tal derecho bajo la protección de la fraternidad en el sentido jurídico-social.

\section{ABSTRACT}

The right to health in Brazil, as our 1988 Federal Constitution points out, is a right of all and a duty of the State, guaranteed through social and economic policies aimed at reducing the risk of disease and other harms and universal and equal access to actions and services for their promotion, protection and recovery. This research aims to analyze the effectiveness of the right to health through access to the right to basic health care, especially public policies

\footnotetext{
1 Artigo elaborado a partir do projeto de pesquisa "A complexa efetivação do direito à atenção básica em saúde no Brasil: paradoxos teóricos e normativos", apoiado pelo PIBIC/CNPq, a ser desenvolvido no período de agosto de 2018 à julho de 2021, junto ao Programa de Pós Graduação em Direito - Mestrado e Doutorado em Direitos Humanos da Unijui/RS.

2 Graduanda em Direito pela UNIJUI. Bolsista PIBIC/CNPq do projeto "A complexa efetivação do direito à atenção básica em saúde no Brasil: paradoxos teóricos e normativos”. E-mail: giovanaknorst@gmail.com; ORCID iD: https://orcid.org/0000-0001-9619-1275.

3 Graduanda em Direito pela UNIJUI. Bolsista PIBIC/CNPq do projeto "A complexa efetivação do direito à atenção básica em saúde no Brasil: paradoxos teóricos e normativos”. E-mail: laisdockorn@gmail.com; ORCID iD: https://orcid.org/0000-0001-8653-3024.

4 Pós doutora em Direito pelo Programa de Pós-Graduação em Direito da Universidade do Vale do Rio dos Sinos - UNISINOS. Doutora em Direito pela Escola Internacional de Doutorado em Direito e Economia Tullio Ascarelli, da Universidade de Roma Tre/Itália. Mestre em Direito pela Universidade de Santa Cruz do Sul - UNISC. Especialista em Demandas Sociais e Políticas Públicas também pela UNISC. Graduada em Direito pela UNISC. Professora na Universidade Regional do Noroeste do Estado do Rio Grande do Sul - UNIJUÍ, lecionando na graduação em Direito e no Programa de Pós Graduação em Direito - Mestrado e Doutorado. Integrante do Grupo de Pesquisa Biopolítica e Direitos Humanos (CNPq). E-mail: janasturza@hotmail.com; ORCID iD: http://orcid.org/0000-001-9290-1380.
} 
articulated and promoted by the Ministry of Health. This study will be conducted from the reflective perspective of the theories of Fraternal Law and Living Law, to demonstrate that the right to health is a common good for all, in this scenario, the necessary realization of such a right under the protection of the fraternity in the juridical-social sense.

PALABRAS CLAVE: Dignidad Humana; Políticas públicas; Ley Viva;

Ley Fraterna.

KEY WORDS: Human dignity; Public policy; Living Law; Fraternal Law.

\section{Introdução}

O presente projeto objetiva fazer uma análise do direito fundamental social à saúde, em especial às políticas públicas articuladas e fomentadas pelo Ministério da Saúde para garantir e promover o acesso à atenção básica em saúde como parte do direito à saúde. Para tanto, utilizar-se-á o aporte teórico e normativo pós Constituição de 1988, buscando especialmente conhecer as políticas públicas do sistema público de saúde no Brasil. Tal estudo será realizado sob a perspectiva reflexiva das teorias do Direito Fraterno e do Direito Vivo, considerando-se que os direitos sociais são direitos humanos fundamentais no senso jurídico, uma vez que são direitos que tem como escopo a índole social do ser humano, além de serem exigências que brotam da condição de sermos membros ativos e solidários de um grupo social.

\section{O reconhecimento do Direito à Saúde como direito fundamental após a Consti- tuição de 1988}

Após o fim da $2^{a}$ Guerra Mundial, foi promulgada a Declaração Universal dos Direitos do Homem (DUDH), em 10 de dezembro de 1948, reconhecendo que todos os seres humanos nascem livres e iguais em dignidade e direitos, dotados de razão e consciência, devendo agir com espírito de fraternidade. Em 1966, mais dois importantes documentos são adotados e proclamados pela Assembleia das Nações Unidas, formando a Carta Internacional dos Direitos do Homem: o Pacto Internacional sobre Direitos Econômicos, Sociais e Econômicos (PIDESC), e o Pacto Internacional sobre os Direitos Civis e Políticos (PIDCP), (ONU, 1966), ambos afirmando que a dignidade é inerente a todos os membros da família humana, e seus direitos são iguais e inalienáveis, constituindo fundamento da liberdade, da justiça e da paz no Mundo, dando início ao fenômeno da internacionalização e universalização dos direitos humanos (BRASIL, 2002).

Em 1960 teve início a discussão sobre a determinação econômica e social da saúde, buscando superar a acepção do termo saúde centrada no controle da enfermidade. Foi a partir da Conferência da Alma-Ata em 1978, que se definiram os principais aspectos para o desenvolvimento do direito à saúde. Com os ventos trazidos pela redemocratização do país, o $1^{\circ}$ Simpósio sobre Política Nacional de Saúde, em 1979, lançou os princípios da Reforma Sanitária inspirados por Alma-Ata. Em 1986, a $8^{a}$ Conferência Nacional de Saúde, influenciada pela Carta de Ottawa, firmou o entendimento da necessidade de reformulação mais profunda da saúde, a partir da ampliação de conceito de saúde. Após inúmeros embates, prevaleceu o entendimento que saúde é a "resultante das condições de alimentação, habitação, educação, renda, meio ambiente, trabalho, transporte, em- 
prego, lazer, liberdade, acesso e posse da terra e acesso a serviços de saúde". Assim, o foco do atendimento à saúde passou a ser o desenvolvimento adequado das condições sanitárias, sociais e econômicas. O produto final era a saúde, mas os meios para atingi-la dependeriam de um conjunto de ações estatais. Para atingir esse objetivo, foi aprovada a formação da Comissão Nacional da Reforma Sanitária, responsável pela elaboração de proposta, norteada pelo novo conceito de saúde, para subsidiar a Constituinte, o que acabou por resultar na criação do SUS e na aprovação do texto final do artigo 196 da Constituição de 1988:

A saúde é direito de todos e dever do Estado, garantido mediante políticas sociais e econômicas que visem à redução do risco de doença e de outros agravos e ao acesso universal e igualitário às ações e serviços para sua promoção, proteção e recuperação (BRASIL, [s.d.]).

Destarte, a Constituição de 1988 assegura a todos o direito à saúde, que deverá ser desenvolvido através de políticas públicas garantindo a universalidade e a igualdade no acesso aos serviços de saúde. Esse direito encontra-se intimamente conectado com a cidadania e a dignidade humana, fundamentos do Estado Democrático de Direito conforme artigo $1^{\circ}$, incisos II e III da CF/88, bem como ao projeto constitucional de construção de uma sociedade livre, justa e solidária, de desenvolvimento nacional e da erradicação da pobreza e marginalização, objetivos fundamentais da República Federativa do Brasil, elencados no artigo $2^{\circ}$, incisos I, II e III da CF/88.

Enquanto os direitos humanos de concepção liberal foram construídos historicamente para conter as ações abusivas do Estado em relação aos indivíduos, configurando um direito de resistência, os direitos econômicos, sociais e culturais, de agora em diante apenas direitos sociais, emergem das tensões sociais vividas a partir do século XIX com a Revolução Industrial, que passou a impor, por exemplo, um regime de trabalho que envolvia crianças, adultos e idosos, indistintamente. Esse ambiente de exploração do trabalho humano reforçou a insatisfação social no decorrer do século XIX, gerando movimentos reivindicatórios de sociedades autônomas, como sindicatos e grupos de apoio, e encontrando grandes barreiras econômicas e políticas. Frankenberg (1997, p. 14) explica:

O Bem-Estar como assistência pública sucumbiu à política do laissez faire. As obrigações da sociedade para com o miserável e desafortunado foram interpretadas como uma ameaça que prejudicava o princípio da concorrência e o funcionamento do Mercado de trabalho. A sociedade de Mercado de concorrentes isolados ofuscou a sociedade dos indivíduos mutuamente responsáveis; ao longo do século XIX o individualismo possessivo, sob o pretexto de liberdade prevaleceu sobre a fraternidade/solidariedade e os direitos sociais.

Diante dessas enormes dificuldades, no final do século XIX, organizações de trabalhadores na Inglaterra, avançaram na ideia de desenvolver autoajuda, com a criação de fundos, baseados em contribuições voluntárias, cujos benefícios seriam pagos no caso de enfermidades e velhice aos membros, viúvas e órfãos, além de oferecerem serviços funerários e locais para lazer. Mas, foi no início do século XX, que os direitos sociais avançaram, com sua positivação em diversas constituições: Constituição Mexicana de 1917, Constituição de Weimar de 1919, Constituição Espanhola de 1931, Constituição Russa 
de 1936 e Constituição da Irlanda de 1937. Em relação à positivação nas constituições brasileiras, assinala-se a previsão do direito ao trabalho na Constituição Imperial de 1824 (artigo 179, inciso XXIV) e a omissão a respeito a qualquer direito social na Constituição Republicana de 1891. Foi a partir da Constituição de 1934 que se consagraram alguns direitos sociais, positivação que se verificou nas Constituições de 1937, 1946, 1967, 1969 e 1988. A positivação dos direitos sociais antecedeu uma série de eventos ocorridos no pós-guerra. Somente com a execução do relatório pelo Governo Trabalhista.

O direito à saúde no Brasil só foi positivado com a Constituição de 1988. Até então, a preocupação do constituinte com a saúde deu-se de forma esparsa, inconsistente, sem vestígio de qualquer sistematização do desenvolvimento da saúde para a nação, ressalvando-se a Constituição de 1969, que estabelece competência originária legislativa sobre saúde para a União, e suplementar para os Estados, bem como competência material para a União desenvolver plano nacional de saúde. Incluído no rol dos direitos sociais do artigo $6^{\circ}$ pelo constituinte originário de 1988 , vincula-se imediatamente aos dispositivos dos artigos 196 a 200 da Carta, onde encontrou maior concretização normativa, com previsão de vasta legislação infraconstitucional. Trata-se de normas de natureza programática, assim definidas didaticamente por José Afonso da Silva (2001, p. 138):

[...] normas constitucionais através das quais o constituinte, em vez de regular, direta e imediatamente, determinados interesses, limitou-se a traçar-lhes os princípios para serem cumpridos pelos seus órgãos (legislativo, executivos, jurisdicionais e administrativos), como programas das respectivas atividades, visando à realização dos fins sociais do Estado.

As normas que disciplinam o direito à saúde se caracterizam como normas programáticas, ou normas-tarefas, de cunho impositivo, de forma que não há como se negar seu caráter obrigatório, que impõem aos poderes públicos uma série de tarefas para realizar o projeto do constituinte, notadamente dependente de intermediação legislativa. Canotilho (2003, p. 1177) cita três características importantes das normas programáticas:

Vinculação do legislador de forma permanente, à sua realização (imposição constitucional); (2) vinculação positiva de todos os órgãos concretizadores, devendo estes toma-las em consideração como directivas materiais permanente, em qualquer dos momentos da atividade concretizadora (legislação, execução, jurisdição); (3) vinculação, na qualidade de limites materiais negativos, dos poderes públicos, justificando a eventual censura, sob a forma de inconstitucionalidade, em relação aos actos que as contrariam.

Além das grandes disposições constitucionais a disciplinar os direitos sociais, e em especial o direito à saúde, os estudiosos do tema apontam uma série de objeções a esses direitos. Limitamos a abordar três delas, as quais são consideradas importantes para a efetividade do direito à saúde e para o que se pretende explanar quanto ao desenho institucional das doenças negligenciadas. A primeira questionada é a possibilidade de o direito à saúde, assim como os direitos sociais, ser incluído legitimamente no rol dos direitos humano. A segunda constitui na objeção aos direitos sociais, atingindo especialmente o direito à saúde. Ressalta que mesmo que se empreendam todos os esforços 
disponíveis, não será possível realizar todos os direitos sociais para todos os indivíduos, significando dizer que nem todos os cidadãos receberão adequadamente todos os serviços de saúde de que necessitam. Essa crítica se encaminha para a discussão sobre a reserva do possível, crítica financeira formulada a partir de uma norma do PIDESC (artigo $2^{\circ}, 1$ ), onde ficou consignado progressiva para assegurar o pleno exercício dos direitos reconhecidos no Pacto. Todavia, é esses recursos são insuficientes para atender todas as necessidades de saúde, impondo aos poderes públicos a tarefa de escolher onde investir os escassos recursos disponíveis, já que o orçamento público se apresenta habitualmente aquém da demanda social (SARLET, 2005).

Desta forma, a saída para aqueles que não têm acesso aos cuidados necessários à sua saúde, como o fornecimento de medicamentos, terapias especializadas e outras medidas, tem sido buscar no Poder Judiciário a solução do problema, apresentando-se a terceira objeção aos direitos sociais, qual seja, a da judicialização excessiva. Sabe-se que a jurisdição é inerte, e que uma vez provocada, não pode deixar de decidir sobre a pretensão do autor. Por outro lado, o desenho institucional do direito à saúde estabelecido pelo constituinte originário, prescrito a partir do artigo 196 da Constituição de 1988, endereçou a responsabilidade para a realização do direito à saúde ao Poder Executivo, que deverá fazê-lo através de políticas sociais e econômicas.

\title{
III. Direito Vivo e Direito Fraterno: Princípios gerais
}

A sociologia do Direito parte da premissa do estudo do Direito Vivo, que de acordo com Eugen Ehrlich, também influenciado pelo movimento do direito livre. A expressão “Direito vivo", empregada por Ehrlich, denota que o Direito não se encontra nas proposições jurídicas, genéricas, abstratas e sucintas, mas na complexidade, dinâmica, abrangência e particularidade das relações em sociedade. Dessa Forma, Ehrlich (2002. p.109-115) esclarece que:

\begin{abstract}
As relações jurídicas, das quais os códigos tratam, tão incomparavelmente mais ricas, mais variadas, mais cambiantes, como elas nunca foram, que o simples pensamento de esgotá-las em um código seria uma monstruosidade. Querer encerrar todo o direito de um tempo ou de um povo nos parágrafos de um código é tão razoável quanto querer prender uma correnteza numa lagoa.
\end{abstract}

Pode-se notar que o Direito vivo deve ser investigado por meio da observação e buscado nos documentos modernos, pois o Direito vivo não depende do Estado para surgir e se desenvolver, mas da realidade social. Ele emana da própria sociedade, das organizações sociais, e é a base da ordem jurídica da sociedade humana.

Através do Direito Vivo podemos pensar na teoria do Direto Fraterno, o qual segundo Eligio Resta, a ideia de fraternidade anunciada na Declaração Universal dos Direitos do Homem, evidenciando as várias facetas modernas que escondem o verdadeiro sentido da fraternidade, conforme o autor (Resta, 2002, p. 07):

La fraternità illuministica reimmette uma certa quota di complessità nel freddo primato del giusto sul buono e cerca, appunto, di alimentare di passioni calde il clima rigido delle relazione politiche. Ma ha nello stesso tempo bisogno di trasferire il modello dell'amicizia ne- 
Ila dimensione della fraternità, tipica di una condivisione di destini grazie alla nascita e indipendentemente delle differenze. Per questo ha bisogno di transformarla in codice, di farne regola; con tutti i paradossi, ma anche con tutte le aperture che comporta. Per questo è "diritto fraterno" che si affaccia allora, in epoca illuministica, e vive da quel momento in poi come condizione esclusa, ma non eliminata, accantonata e presente nello stesso tempo.

Dessa forma, vem a ideia de um modelo de direito que abandona os limites fechados da cidadania e projeta para uma nova forma de aplicação do direito como observa Barrata (2006, p.64-65).

[...] Perché solo con un grande sforzo teorico e pratico di tutti, giuristi e non, si può giungere alla construzione di un nuovo sapere collettivo, del diritto e sul diritto adeguato alla situazione umana del nostro tempo.[...] Nuovi rischi, come quelli ricollegabili alle immissioni nella atmosfera ou nelle acque, alla ingegneria genetica, alla energia nucleare, allo sfruttamento delle risorse naturali, al trattamento delle scorie e dei rifi uti, al traffi co, all'uso dei mezzi di comunicazione e di elaborazione dei dati, fanno parte oramai dei connotati strutturali della situazione umana e dell'ecosistema. Essi sono anche il luogo speciale in cui, nell'incontro tra la (riga illegibile), può emergere una nuova forma di pensare e di fare il diritto.

Através dessa aposta apresentada por Barrata, se tem possibilidade do Direito Fraterno, enquanto nova proposta, na qual a construção de um novo saber passa necessariamente por uma visão que ultrapassa, mas não esquece os limites dos juristas e não juristas, os limites da ciência do direito frente às novas demandas que surgem. Podemos perceber que o direito tradicionalmente construído não consegue dar respostas adequadas para novos desafios que envolvem o ser no e para o mundo.

\section{Direito à Saúde com base no princípio fraterno}

A partir da Declaração Universal dos Direitos Humanos de 1948, em seu artigo $1^{\circ}$, destaca a fraternidade com o sentido de responsabilidade, pois menciona: "Todas as pessoas nascem livres e iguais em dignidade e direitos. São dotadas de razão e consciência e devem agir em relação umas às outras com espírito de fraternidade". Porém, este princípio encontra-se no teor do Preâmbulo da Constituição Federal brasileira 1988, que expressa:

Nós, representantes do povo brasileiro, reunidos em Assembleia Nacional Constituinte para instituir um Estado Democrático, destinado a assegurar o exercício dos direitos sociais e individuais, a liberdade, a segurança, o bem-estar, o desenvolvimento, a igualdade e a justiça como valores supremos de uma sociedade fraterna, pluralista e sem preconceitos, fundada na harmonia social e comprometida, na ordem interna e internacional, com a solução pacífica das controvérsias, promulgamos, sob a proteção de Deus, a seguinte CONSTITUIÇÃO DA REPÚBLICA FEDERATIVA DO BRASIL.

Percebe-se que o legislador resgata formalmente, através do texto, o princípio esqueci- 
do pela modernidade. Desta forma a carta magna menciona que a sociedade fraterna nada mais é do que uma sociedade sem preconceitos e pluralista. É neste sentido que a saúde se alicerça no direito fraterno, como menciona Eligio Resta (2002, p. 51):

A saúde sempre foi tema em destaque em qualquer sociedade e em qualquer período. Atualmente, as discussões têm tomado novas dimensões, já que vivemos em uma sociedade complexa, num mundo globalizado, na era da inclusão universal. A era dos direitos não coincide com o acesso a estes direitos; por isso, os mais diversos sistemas sociais devem constantemente responder a demandas de complexidade crescente. O sistema do direito, que por muito tempo ficou distante do sistema de saúde, passa a ter uma função importante na efetivação do direito fundamental à saúde. Assim, o direito, como afirma Resta, não pode mais estar ligado aos confins do próprio estado, mas precisa ultrapassar os limites geográficos e políticos para que efetivamente tenhamos uma dimensão fraterna no convívio social.

Nesta seara, o direito fraterno revela-se como uma peça fundamental para se aproximar do acesso à saúde, buscando uma efetivação dos direitos fundamentais. Compreende nessa perspectiva que "[...] o Direito Fraterno prima pela análise transdisciplinar dos fenômenos sociais. A transdisciplinariedade significa, antes de tudo, transgredir e, ao mesmo tempo, integrar [...]" (Resta, 2006, p. 7-51). Desse modo, a partir do entendimento de Lafayette Pozzoli (2011, p. 287) entende que o Direito Fraterno seria:

Uma modalidade do direito que ainda não está consolidado como paradigma e/ou teoria, mas como abordagem. Abordagem esta que propõe uma nova forma de análise do direito atual, mas do que isto, propõe uma reestruturação de todas as políticas públicas que pretendam uma inclusão universal. Todo o pensamento apresentado pelo autor Resta tem um grande valor científico, e o é, na nossa percepção, uma abordagem científica do e para o direito atual. Assim, dentro dessa nova abordagem, necessita-se de uma análise transdisciplinar dos fenômenos sociais. A transdisciplinariedade significa antes de tudo, transgredir e, ao mesmo tempo, integrar. Transgredir, no sentido de buscar, nas diversas ciências, os fundamentos e os pressupostos para captar, conforme Weber, o sentido subjetivo das ações sociais e, portanto, das ações jurídicas. Integrar no sentido de que é preciso analisar o contexto do todo e não em partes separadas.

Destarte, as políticas relacionadas à saúde pública não devem esquecer-se desse do princípio fraternal. Pois o direito fraterno caminha em direção aos Direitos Humanos e, especialmente, percorre essa direção com a real necessidade de sua universalização, como mencionado por Sandra Regina Martini Vial (2013, n. 5):

Vislumbra-se que o Direito Fraterno está no âmbito dos temas referentes aos Direitos Humanos e da necessidade de sua universalização. Estes se destinam a todo e qualquer ser humano, não porque pertença a um ou outro território, siga esta ou aquela cultura ou, ain- 
da, tenha uma descendência determinada, mas tão somente porque tem humanidade. É um direito que tem como fundamento a humanidade, o "ter humanidade", uma humanidade repleta de diferenças compartilhadas e de uma comunhão de juramentos, de comprometimentos, de responsabilidade.

Vale ressaltar a presença de um constitucionalismo fraternal, sendo que grande parte da história do Direito Constitucional segue contida de fases, ou seja, primeiramente veio o Estado de Direito, logo, entrou em destaque o Estado Democrático de Direito, a partir desse apareceu o Estado de Direito Democrático e, hoje, vem à tona o Estado Holístico, ou melhor, o Estado de Funcionalidade Fraternal.

Dessa forma em torno da efetivação do ideário constitucionalista deve-se refletir sobre discursos da abstração, pois a fraternidade abrange uma ação pautada pelo reconhecimento do outro, e é este reconhecimento do outro que impõe a origem de condições institucionais que viabilizem os direitos fundamentais. O constitucionalismo fraternal busca ampliar os sujeitos responsáveis pela concretização dos direitos fundamentais, sem diminuir a responsabilidade dos Poderes Públicos.

\section{V. $O$ direito à saúde e a importância de Políticas Públicas}

A criação de políticas públicas voltadas a saúde é o meio mais adequado para a realização do direito à saúde. Conforme indicado no artigo 196 da Carta Constitucional, a implementação de políticas públicas é fundamental para reduzir o risco de doença, focando nas ações preventivas e no atendimento básico de saúde, bem como no acesso universal igualitário, o que aponta para um dos objetivos fundamentais da República Federativa do Brasil, qual seja, o de "erradicar a pobreza e a marginalização e reduzir as desigualdades sociais e regionais". (Artigo 30, inciso III da Constituição de 1988). Essas disposições normativas encontram-se em harmonia com o Preâmbulo da Constituição da Organização Mundial de Saúde, ao enunciar que "Saúde é o completo estado de bemestar físico, mental e social e não a mera ausência de doença ou enfermidade" e que "Governos têm responsabilidade para com a saúde dos seus povos, que podem ser satisfeitas somente pela prestação de saúde adequada e medidas sociais" (OMS/WHO, 2004).

Como já mencionado os direitos humanos para a saúde incorpora outros aspectos que devem ser desenvolvidos junto à saúde. Desta maneira, as políticas públicas de saúde, não se realizam pontualmente, isoladamente, mas sim constituem um processo dinâmico e integrado que envolve moradia, trabalho, educação e investimento, contribuindo para o desenvolvimento do país.

Nesse contexto, as políticas públicas conheceram grande impulso a partir da inclusão dos direitos sociais na agenda constitucional e dos inúmeros organismos internacionais que se dedicam a esses direitos (ZIMMERMANN, 2006, p.144-159), constituindo-se em instrumentos realizadores das tarefas governamentais. As políticas públicas têm de significar, antes de tudo, a reafirmação e consolidação de uma cultura de direitos humanos no Brasil, e isso, sem dúvida, passa pela construção e implantação de políticas que envolvam a participação de diversos atores sociais. Por um lado, o Estado deve assumir a responsabilidade de integrar as políticas de saúde às políticas sociais e econômicas, engajando-se na promoção da melhoria das condições de vida mais digna e o pleno exercício da cidadania (CAMPOS; BARROS; CASTRO, 2004, p. 746-747). 
A inclusão de diversos atores sociais como, usuários, profissionais da saúde, empresas, representantes de organizações civis como, protagonistas no processo produtivo da saúde, torna a promoção da saúde importante resposta à medida que destaca ações intersetoriais como estratégia de enfrentamento dos problemas quanto ao meio ambiente, à urbanização, à segurança alimentar e nutricional, ao desemprego, à moradia, ao uso de drogas ilícitas, etc.

As questões de saúde pública também passaram a fazer parte da esfera privada de atores sociais até então indiferentes a esses problemas, entendidos por eles como de responsabilidade e exclusiva do Estado. Essa preocupação foi externada pela Organização Pan-Americana da Saúde (OPAS), do Ministério da Saúde (MS) e do Conselho Nacional da Saúde (CNS), no documento Inclusão dos Cidadãos na Implementação das Políticas de Saúde de 2012. A parceria firmada entre a OPAS e o CNS fortaleceu a participação e controle social no âmbito do SUS. Os laboratórios de Inovação, que representam "uma estratégia para promover e valorizar o desenvolvimento da gestão em saúde, aí incluído o processo de participação e controle pela sociedade" (Ministério da Saúde, 2009), pois são atividades de cooperação técnica que se destacam. Nesse sentido as políticas de saúde, vem se desenvolvendo cada vez mais rápido em decorrência da ampliação do conceito de saúde, que passou a ser compreendido como um Fenômeno político, que em um ambiente de liberdade evidencia as necessidades em saúde.

Contudo podemos perceber que o direito à saúde desenvolvido no ambiente do Estado do bem-estar social, por meio de normas programáticas, ou normas-tarefas, que exigem do Estado o desenvolvimento de diversas atividades, não se realiza sozinho. Pois são essas normas que caracterizam a constituição programática, aquela que define um plano de ação para o Estado, legitimando, portanto, sua ação social. Como já mencionado o Direito à Saúde e sua efetivação é conquista recente no constitucionalismo, a qual procurou superar algumas deficiências da normatização constitucional.

\section{Atenção Básica em Saúde}

A Política Nacional de Atenção Básica (PNAB) é resultado da experiência acumulada pelo conjunto de fatores (movimentos sociais, usuários, trabalhadores e gestores das três esferas de governo) envolvidos historicamente com o desenvolvimento e a consolidação do Sistema Único de Saúde (SUS). No Brasil, a Atenção Básica é desenvolvida com o mais alto grau de descentralização e capilaridade, ocorrendo no local mais próximo da vida das pessoas. Ela deve ser o contato preferencial dos usuários, a principal porta de entrada e centro de comunicação com toda a Rede de Atenção à Saúde. Por isso, é fundamental que ela se oriente pelos princípios da universalidade, da acessibilidade, do vínculo, da continuidade do cuidado, da integralidade da atenção, da responsabilização, da humanização, da equidade e da participação social (Ministério da Saúde, 2009).

A atenção básica é caracterizada por um conjunto de ações de saúde, no âmbito individual e coletivo, que abrange a promoção e a proteção da saúde, a prevenção de agravos, o diagnóstico, o tratamento, a reabilitação, a redução de danos e a manutenção da saúde com o objetivo de desenvolver uma atenção integral que impacte na situação de saúde e autonomia das pessoas e nos determinantes e condicionantes de saúde das coletividades (Ministério da Saúde, 2009).

É desenvolvida com fundamentos em várias diretrizes que por meio do exercício de prá- 
ticas de cuidado e gestão, democráticas e participativas, sob forma de trabalho em equipe, dirigidas a populações de territórios definidos assumindo responsabilidade sanitária, considerando a dinamicidade existente no território em que vivem essas populações. Dessa forma são utilizadas tecnologias complexas e variadas que devem auxiliar as demandas e necessidades de saúde de maior frequência e relevância em seu território, observando critérios de risco, vulnerabilidade, resiliência e o imperativo ético de que toda demanda, necessidade de saúde ou sofrimento devem ser acolhidos.

Conforme o SUS, a organização de Redes de Atenção à Saúde (RAS) tem como estratégia o cuidado integral direcionado paras às necessidades de saúde da população. As RAS constituem-se em arranjos organizativos formados por ações e serviços de saúde com diferentes configurações tecnológicas e missões assistenciais, articulados de forma complementar e com base territorial (Brasil, Ministério da Saúde, 1990). Tem diversos atributos, entre eles, destaca-se: a atenção básica estruturada como primeiro ponto de atenção e principal porta de entrada do sistema, constituída de equipe multidisciplinar que cobre toda a população, integrando, coordenando o cuidado e atendendo às suas necessidades de saúde. O Decreto $n^{\circ} 7.508$, de 28 de julho de 2011, que regulamenta a Lei $n^{\circ} 8.080 / 90$, define que "o acesso universal, igualitário e ordenado às ações e serviços de saúde se inicia pelas portas de entrada do SUS e se completa na rede regionalizada e hierarquizada". Nesse sentido, a atenção básica deve cumprir algumas funções para contribuir com o funcionamento das Redes de Atenção à Saúde, conforme estabelece o Ministério da Saúde (2011):

1 - Ser base: ser a modalidade de atenção e de serviço de saúde com o mais elevado grau de descentralização e capilaridade, cuja participação no cuidado se faz sempre necessária;

2 - Ser resolutiva: identificar riscos, necessidades e demandas de saúde, utilizando e articulando diferentes tecnologias de cuidado individual e coletivo, por meio de uma clínica ampliada capaz de construir vínculos positivos e intervenções clínica e sanitáriaMinistério da Saúde, Secretaria de Atenção à Saúde Departamento de Atenção Básica - efetivas, na perspectiva de ampliação dos graus de autonomia dos indivíduos e grupos sociais;

3 - Coordenar o cuidado: elaborar, acompanhar e gerir projetos terapêuticos singulares, bem como acompanhar e organizar o fluxo dos usuários entre os pontos de atenção das RAS. Atuando como o centro de comunicação entre os diversos pontos de atenção, responsabilizando-se pelo cuidado dos usuários por meio de uma relação horizontal, contínua e integrada, com o objetivo de produzir a gestão compartilhada da atenção integral. Articulando também as outras estruturas das redes de saúde e intersetoriais, públicas, comunitárias e sociais. Para isso, é necessário incorporar ferramentas e dispositivos de gestão do cuidado, tais como: gestão das listas de espera (encaminhamentos para consultas especializadas, procedimentos e exames), prontuário eletrônico em rede, protocolos de atenção organizados sob a lógica de linhas de cuidado, discussão e análise de casos traçadores, eventos- -sentinela e incidentes críticos, entre outros. As práticas de regulação realizadas na atenção básica devem ser articuladas com os processos regulatórios realizados em outros espaços da rede, de modo a permitir, ao mesmo tempo, a qualidade da microrregulação realizada pelos profissionais da atenção básica e o acesso a outros pontos de atenção nas condições e no tempo adequado, com equidade; e

4 - Ordenar as redes: reconhecer as necessidades de saúde da população sob sua responsabilidade, organizando-as em relação aos outros pontos de atenção, contri- 
buindo para que a programação dos serviços de saúde parta das necessidades de saúde dos usuários.

Destarte, conclui-se que o Estado tem a obrigação de garantir aos cidadãos programas de atenção básica principalmente relacionada a saúde. Esses mecanismos devem ser cuidadosamente efetivados em todas as regiões do país, sem qualquer discriminação, pois o objetivo é fornecer o serviço mais adequado para suprir as necessidades dos usuários desse sistema público.

\section{Conclusão}

Diante do que foi exposto nesse estudo, podemos perceber que nos tempos modernos, o caminho rumo à efetividade das normas programáticas está devidamente assentado, não restando qualquer dúvida sobre seu papel na imposição de tarefas ao Estado no sentido de realizar as expectativas da sociedade, em especial, do direito à saúde, por meio do desenvolvimento de políticas públicas. Essas políticas públicas de saúde são projetos elaborados pelo Poder Público, com o auxílio de entes públicos e privados, com o objetivo de preservar o direito à saúde. O Sistema Único de Saúde é uma política pública de saúde, com princípios compatíveis aos descritos na Constituição Federal de 1988, podemos dizer até que tratam-se de "subprincípios", uma vez que estão inseridos nos princípios estabelecidos na Constituição Federal. Desta forma, as teorias do direito vivo juntamente com o direito fraterno são essenciais para a preservação dos direitos sociais considerando que são direitos fundamentais. Essas teorias são o alicerce para a criação das políticas públicas de direito a saúde.

\section{REFERÊNCIAS BIBLIOGRÁFICAS}

- ARANTES, Rogério (2005): Judiciário: entre a justiça e a política. In AVELAR, Lúcia; CINTRA, Antônio Octávio (organizadores). Sistema político brasileiro: uma introdução. Rio de Janeiro/São Paulo: Fundação Konrad Adenauer/UNESP, Cap. 3, p. 79-108.

- ARDIGÒ, Achille (org.) (1981): Per uma sociologia della salute. Milano: Franco Angeli.

- BANCO INTERAMERICANO DE DESENVOLVIMENTO (2007): A política das políticas públicas: progresso econômico e social na América Latina: relatório 2006. Rio de Janeiro: Elsevier; Washington, DC: BID.

- BERTUETTI, Gaspare (2001): Danno del congiunto e danno alla salute. Padova: CEDAM.

- BOMPIANI, Adriano (1996): Considerazioni in merito alla politica di sicurezza sociale nel settore dell'assistenza e della sanità. Rimini: Maggioli.

- BONETI, Lindomar W (2006): Políticas públicas por dentro. ljuí: Ed. Unijuí.

- BRAVO, Maria I. e PEREIRA, Potyara A (2001): Política social e democracia. São Paulo: Cortez, Rio de Janeiro: UERJ.

- BRESCIANI, Luca. (1996): Tutela della salute. Pisa: ETS.

- BUCCl, Maria Paula Dallari (2001): Buscando um conceito de políticas públicas para a concretização dos direitos humanos. Disponível em: <http://www.dhnet.org.br/direitos/ textos/politicapublica/mariadallari.htm>. Acesso em: abr. 2008.

-___ (2002): Políticas públicas e direito administrativo. In: Direito administrativo e políticas públicas. São Paulo: Saraiva. 
- BUZZANCA, Adriano (2006): Tutela urgente alla salute e liste di attesa - Aspetti civili, penali e ammnistrativi. Milano: Giuffrè.

- CARVALHO, Alysson et al (2002): Políticas públicas. Belo Horizonte: Ed. UFMG, Proex.

- CARVALHO, Maria C.; TEIXEIRA, Ana C. (org.) (2000): Conselhos gestores de políticas públicas. São Paulo: Pólis.

- CAVALCANTI, B. S.; RUEDIGER, M. A.; SOBREIRA, R. (org.). (2005): Desenvolvimento e construção nacional: políticas públicas. Rio de Janeiro: Editora FGV.

- CARVALHO, Guido Ivan de; SANTOS, Lenir (1995): Sistema único de saúde. Comentários à Lei Orgânica da Saúde 8.080 de 1990 e 8.142 de 1990. 2. ed. São Paulo: Hucitec.

- COCCONI, Monica (1998): Il diritto alla tutela della salute. Padova: CEDAM.

- DALLARI, Sueli Gandolfi (1987): A saúde do brasileiro. São Paulo Paulo: Editora Moderna.

- ___ (1988): O direito à saúde. Revista de saúde pública. São Paulo, n 22, p. 57-63.

- DIAS, Hélio Pereira (1995): A responsabilidade pela saúde - Aspectos jurídicos. Rio de Janeiro: Fiocruz.

- FARAH, Marta F. S. (2001): Parcerias, novos arranjos institucionais e políticas públicas no Brasil. Revista de administração pública, v. 35, nº 1, p. 119-145.

- FREIRE Jr., Américo B (2005): O controle judicial de políticas públicas. São Paulo: Ed. Revista dos Tribunais.

- FREY, Klaus (2000): Políticas públicas: um debate conceitual e reflexões referentes à prática da análise de políticas públicas no Brasil. Disponível em: <http://www.ipea.gov. br/ppp/index.php/PPP/article/view/89/158>. Acesso em: 3/02/2005.

- FRISCHEISEN, Luiza C. F. (2000): Políticas públicas: a responsabilidade do administrador e o ministério público. São Paulo: Max Limonad.

- FABRIS, Elisabetta Palermo (2000): Diritto alla salute e trattamenti sanitari nel sistema penale: profili problematici del diritto all'autodeterminazione. 2. ed. Padova: Grafiche TPM. - FEBBRAJO, Alberto; SPINA, Antonio La; RAITERI, Monica (2006): Cultura giuridica e poltiche pubbliche in Italia. Milano: Giuffrè.

- FIORIO, Carlo (2002): Libertà personale e diritto alla salute. Padova: CEDAM.

- GIACOMELLI, Ivano; VIGGIANO, Caterina Di (1993): Salute: II diritto e la tutela. Roma: Lampo.

- GOUVEIA, Roberto (2000): Saúde pública, suprema lei - a nova legislação para a conquista da saúde. São Paulo: Mandacaru.

- JORIO, Ettore (2006): Diritto sanitario. Milano: Guiffrè.

- LEAL, Rogério Gesta (2006). O controle jurisdicional de políticas públicas no Brasil: possibilidades materiais. Revista de derecho, v. 9, p. 53-66.

- LEAL, Rogério Gesta (2006): Estado, administração pública e sociedade. Porto Alegre: Livraria do Advogado.

- LEVY, Evelyn; DRAGO, Pedro A. (org.) (2006): Gestão pública no Brasil contemporâneo. São Paulo: Fundap.

- MARTIN, Alessandro; NACCARATO, Remo (1989): Diritto alla salute e coscienza sanitária. Padova: CEDAN.

- MUNIZ, J.N; GOMES, E.C. (ed.) (2002): Participação social e gestão pública: as armadilhas da política de descentralização. Belo Horizonte.

- MORAIS, J. L. B. de; SCHWARTZ, G. A.; PILAU SOBRINHO, L. L (2003): Análise jurídico constitucional do direito à saúde. In: Leal, R. G.; ARAÚJO, L. E. B. de (Org.). Direitos sociais e políticas públicas - desafios contemporâneos. Tomo 2. Santa Cruz do Sul: EDUNISC.

- MORANA, Donatella (2002): La salute nella costituzione italiana: profili sistematici.

Milano: Giuffrè. 